\title{
Hepatoprotective Effect of the Aqueous Leaf Extract of Andrographis paniculata Nees Against Carbon Tetrachloride - Induced Hepatotoxicity in Rats
}

\author{
${ }^{* 1}$ A. Nasir, 1,2M.G. Abubakar, ${ }^{2}$ R.A. Shehu, ${ }^{3}$ U. Aliyu, and ${ }^{4}$ B.K. Toge \\ 1Department of Biochemistry, Umaru Musa Yar'adua University, Katsina, Nigeria. \\ 2Department of Biochemistry, Usmanu Danfodiyo University Sokoto, Nigeria. \\ 3Department of Crop Science, Usmanu Danfodiyo University, Sokoto, Nigeria. \\ ${ }^{4}$ Department of Pharmaceutics, Delta State University, Abraka, Nigeria, \\ [Corresponding author: Email amnuf01@yahoo.com]
}

\begin{abstract}
Hepatoprotective effect of the aqueous leaf extract of Andrographis paniculata was investigated against $\mathrm{CCl}_{4}$ - induced hepatic injury in rats. Significant $(P<0.05)$ increase of serum levels of alanine aminotransferase (ALT), aspartate amino transferase (AST), alkaline phosphatase (ALP), total bilirubin (TBL), direct bilirubin (DBL), total cholesterol (CHL), triglycerides (TG), low density lipoprotein (LDL), very low density lipoprotein (VLDL) and malondialdehyde (MDA) in $\mathrm{CCl}_{4}$ intoxicated rats were restored to normal levels when treated with the extract and $\mathrm{CCl}_{4}$. Significant $(\mathrm{P}<0.05)$ decrease of serum levels of total protein $(\mathrm{TP})$, albumin (ALB), high density lipoprotein ( $\mathrm{HDL}$ ) and reduced glutathione (GSH) in $\mathrm{CCl}_{4}$ intoxicated rats were restored to normal levels when treated with the extract and $\mathrm{CCl}_{4}$. The $\mathrm{LD}_{50}$ of the leaf extract was greater than $3000 \mathrm{mg} / \mathrm{kg}$. The study demonstrated that $A$. paniculata possesses significant hepatoprotective effects and may be the source of lead compound in the management of liver diseases.
\end{abstract}

Key words: Hepatoprotective, Andrographis paniculata, Carbon Tetrachloride, Liver Disease.

\section{INTRODUCTION}

Liver is one of the largest organs in human body and the chief site for intense metabolism and excretion (Ahsan et al., 2009). It is involved with almost all the biochemical pathways to growth, fight against disease, nutrient supply, energy provision and reproduction (Ward and Daly, 1999). So it has a surprising role in the maintenance, performance and homeostasis of the body (Ahsan et al., 2009). Hepatic damage is associated with distortion of these metabolic functions (Wolf, 1999). Liver damage is associated with cellular necrosis, increase in tissue lipid peroxidation and depletion of reduced glutathione levels. In addition, serum levels of many biochemical markers like transaminases, alkaline phosphatase, bilirubin, triglycerides and cholesterol are elevated in liver disease (Mascolo et al., 1988). Liver diseases pose a serious challenge to international public health (Ahsan et al., 2009). Unfortunately, conventional or synthetic drugs used in the treatment of liver diseases are inadequate and sometimes can have serious side effects (Rao et al., 2005). Moreover, there are still no specific treatments in modern medicine that give protection to the liver against damage or help to regenerate hepatic cells (Chatterjee, 2000; Chattopadhyay, 2003).
Recently, the use of medicinal plants to cure various forms of liver diseases and dysfunctions is becoming increasingly popular and has received wide acceptance (Oyagbemi and Odetola, 2010). Moreover, a large number of medicinal plants have been found to offer some hepatoprotection (Handa and Sharma, 1990; Trivedi and Rawal, 2000; Ghosh et al., 2007; Prakash et al., 2008; Khan et al., 2009; Ahsan et al., 2009; Adeneye et al., 2009; Oyagbemi and Odetola, 2010).

Andrographis paniculata Nees is a herbaceous plant, commonly known as "King of Bitters", in the family Acanthaceae (Jarukamjorn and Nemoto, 2008). A. paniculata grows erect to a height of $30-110 \mathrm{~cm}$ with glabrous leaves and white flowers with rose-purple spots on the petals (Sabu, 2006). It grows abundantly in southeastern Asia - India, Pakistan and Indonesia but is cultivated extensively in China, Thailand (Sandberg, 1994), the East and West Indies, and Mauritius (Gupta et al., 1990). Because of its well - known medicinal properties, it is cultivated quite easily. A. paniculata has been used in Asia to treat variety of chronic and infectious diseases (Alpha Omega Labs, 2008). It has been traditionally used as a remedy against diabetes (Norhaida, 1994), hypertension (Ahmad and Asmawi, 1993), inflammation (Patarapanich et al., 2007) and cobra bite (Selvanayagam et al., 1994). Extensive 
research revealed that $A$. paniculata has a surprisingly broad range of pharmacological effects and some of them are extremely beneficial and include anticancer (Kumar et al., 2004), anti HIV (Chang and Yeung, 1988), anti AIDS (Stephen and Comac, 2000), hepatoprotective (Handa and Sharma, 1990) and immunostimulatory (Puri et al., 1993). Other pharmacological effects include; antimalarial (Misra et al., 1992), antityphoid (Sabu, 2006), antiviral (Wiart et al., 2005), antifungal (Sabu, 2006), antibacterial (Mishra et al., 2009), antidiarrhoeal (Gupta et al., 1993), antipyretic (Vedavathy and Rao, 1991), antiinflammatory (Chang and But, 1986), antidiabetic (Zhang and Tan, 2000), antithrombotic (Yeung et al., 1987), cardiovascular (Tan and Zhang, 2004), antivenom (Chang and But, 1986), antifertility (Sakila et al., 2009) and psychopharmacological activity (Mandal et al., 2001). A. paniculata may be a promising treatment for the alleviation of subjective symptoms of respiratory tract infections (Coon and Ernst, 2004). It may also be beneficial for those with chronic fatigue syndrome and fibromyalgia (Khan, 2007).

The aim of the present study was to determine the $L D_{50}$ and the hepatoprotective effect of the aqueous leaf extract of $A$. paniculata against carbon tetrachloride intoxicated rats.

\section{MATERIALS AND METHODS Collection of plant material}

Fresh leaves of $A$. paniculata plant were obtained from University Research Farm (Kwalkwalawa), Usmanu Danfodiyo University Sokoto. The plant was identified at Botany Unit, of the same Institution. A voucher specimen was also deposited in the Herbarium of the same Institution for reference.

\section{Preparation of plant material}

The leaves of $A$. paniculata were thoroughly rinsed in tap water twice. The leaves were open- air -dried under shade, cut into small pieces and pulverised into coarse powder (using pestle and mortar). The powder was stored in an airtight bottle until required.

\section{Preparation of aqueous extract}

Two hundred $(200 \mathrm{~g})$ of the powdered sample was mixed with $2000 \mathrm{ml}$ of distilled water, in a conical flask. The mixture was stirred severally covered overnight at room temperature, filtered using Whatman filter paper $(15 \mathrm{~cm})$. The filtrate was evaporated to complete dryness at $40^{\circ} \mathrm{C}$, producing a fine and chocolate colour solid residue. The dried residue was scrapped, weighed and the percentage yield was calculated. The dried residue was stored in a capped bottle.

From the dried residue, a fresh solution was prepared on each day of the experiment.

\section{Experimental animals}

Wistar rats weighing between 180 to $200 \mathrm{~g}$ were purchased from Animal House, Department of Biological Sciences of Usmanu Danfodiyo University, Sokoto. The animals were kept in metal cages in a well ventilated room and allowed to acclimatize for 14 days. They were fed standard diet (Grand Cereals and Oil Mills Limited, Jos, Nigeria) and were provided clean tap water ad libitum. The experiment was performed according to ethical guidelines of OECD (2001).

\section{Determination of $L D_{50}$}

Aqueous leaf extract of $A$. paniculata (3000 mg $/ \mathrm{kg}$ body weight) was administered orally to five rats (one after the other at an interval of 48 hours) in a single dose using oro-gastric tube. The control group received distilled water. Observations of toxic symptoms were made and recorded systematically, at one, two, four and six hours after administration. The number of survivors was noted after 48 hours for each group of animals. The toxicological effects were assessed on the basis of mortality and expressed as $\mathrm{LD}_{50}$ and calculated using the limit test dose, up and down procedure of Organization for Economic and Cultural Development (OECD, 2001).

\section{Hepatoprotective activity test}

Carbon tetrachloride induction of hepatotoxicity was done according to procedures of Rao et al. (2005) with some modifications.

\section{Experimental design}

A total of 30 rats were used. The rats were randomly divided, into six groups of five rats each, as follows:

Group A (normal control untreated rats) received $1 \mathrm{ml}$ daily dose of liquid paraffin ( $1 \mathrm{ml} / \mathrm{kg}$ body weight, per os) for five days.

Group B, C, D, E, and F were administered standard diet and tap water on day one.

Group B (induction control) were administered 30\% carbon tetrachloride in liquid paraffin $(1 \mathrm{ml} / \mathrm{kg}$ body weight, i.p.) for four days (from day two to five). 
Group C received $30 \% \mathrm{CCl}_{4}$ in liquid paraffin $(1 \mathrm{ml} / \mathrm{kg}$ body weight, i.p.) and Silymarin, a known antihepatotoxic drug (Sigma Chemicals Company USA), at a dose of $100 \mathrm{mg} / \mathrm{kg}$, per os, for four days (from day two to five).

Groups D, E, and F (test groups) were treated with $30 \%$ $\mathrm{CCl}_{4}$ in liquid paraffin ( $1 \mathrm{ml} / \mathrm{kg}$ body weight, i.p.) and a daily dose of 100,200 and $300 \mathrm{mg} / \mathrm{kg}$ body weight (orally) of aqueous leaf extract of $A$. paniculata respectively, for four days (from day two to five).

\section{Clinical chemistry}

On the sixth day, all the animals were sacrificed under chloroform anaesthesia and blood and liver samples were collected. The blood collected was allowed to clot for 30 minutes. Serum was separated by centrifuging at $3000 \mathrm{rmp}$ for 5 minutes. The supernatant was collected using Pasteur pipette into the sample bottles. The serum was used for biochemical estimations. Section of the liver was perfused with cold $0.86 \% \mathrm{KCl}$, homogenised, and centrifuged to obtain post mitochondrial supernatant for estimation of liver reduced glutathione and malondialdehyde content. The activities of serum transaminases (ALT and AST), alkaline phosphatase, albumin, total protein, bilirubin (total and direct), total cholesterol, triglycerides and high density lipoprotein were assayed by Randox (assay kit) methods of Reitman and Frankel (1957), Sood (1999), Doumas et al. (1971), Gornall et al. (1949), Jendrassik and Grof (1938), Trinder (1969), Tietz (1990), and Lopez-Virella et al. (1977) respectively. Serum levels of low density lipoprotein and very low density lipoprotein were calculated by using Friedewald formula (Friedewald et al., 1972). Post mitochondrial supernatant was used for the assay of reduced glutathione and malondialdehyde content by the methods of Patterson and Lazarow (1955) and Hartman (1983) respectively.

\section{RESULTS AND DISCUSSION}

Groups of rats treated with $\mathrm{CCl}_{4}$ exhibited significant $(p<0.05)$ increase in the activity of alanine aminotransferase (ALT), aspartate amino transferase (AST), total bilirubin (TBL), direct bilirubin (DBL) and alkaline phosphatase (ALP) when compared to normal control rats. However, serum total protein (TP) and albumin (ALB) were significantly $(p<0.05)$ reduced in $\mathrm{CCl}_{4}$ - treated rats (Table 1 ).
Table 2 shows that groups of rats treated with $\mathrm{CCl}_{4}$ demonstrated significant $(\mathrm{p}<0.05)$ increase in the serum levels of total cholesterol (CHL), triglycerides (TG), low density lipoprotein (LDL), very low density lipoprotein (VLDL) and malondialdehyde (MDA) when compared to normal control rats. However, serum levels of high density lipoprotein (HDL) and reduced glutathione (GSH) were significantly reduced in $\mathrm{CCl}_{4}$ - treated rats.

Acute toxicity test at $3000 \mathrm{mg} / \mathrm{kg}$ body weight of aqueous leaf extract of $A$. paniculata produced no mortality after 48 hours of observation. The median lethal dosage $\left(L D_{50}\right)$ of the aqueous leaf extract was therefore estimated to be greater than $3000 \mathrm{mg} / \mathrm{kg}$ body weight. The extract did not produce any negative behavioural changes such as restlessness, excitement, respiratory distress, convulsions or coma. However, a reduction in weight of the rats was observed. The reduction in weight might be due to reduced food and water intake, which might be secondary to feeling of fullness and loss of appetite after administration (Joseph et al., 1989). Despite the listed side effects, the high value of the $L D_{50}$ showed that the aqueous leaf extract of $A$. paniculata was practically non-toxic.

Carbon tetrachloride is a simple molecule which, when administered to a variety of species, causes centrilobular hepatic necrosis and fatty liver. Low doses of carbon tetrachloride cause only fatty liver and destruction of hepatic cytochrome P-450. However, chronic administration or exposure leads to liver cirrhosis and in some instances liver cancer and kidney damage (Timbrell, 1987). Simultaneous administration of the plant extract and $\mathrm{CCl}_{4}$ produced an effect that was almost similar to that produced by silymarin. The ability of a hepatoprotective drug to reduce the injurious effects or to preserve the normal hepatic physiological mechanisms which have been disturbed by a hepatotoxin is the index of its protective value (Yadav and Dixit, 2003). The hepatotoxic effects induced by $\mathrm{CCl}_{4}$ arise from its metabolite $\cdot \mathrm{CCl}_{3}$, a free radical that alkylates cellular proteins and other macromolecules with a simultaneous attack on polyunsaturated fatty acids, in the presence of oxygen, to produce lipid peroxides, leading to liver damage (Bishayee et al.,1995; Nan et al., 2002). As shown in Table 1, induction of hepatic damage with $\mathrm{CCl}_{4}$ was marked by a significant $(P<0.05)$ increase in serum levels of marker enzymes ( ALT, AST and ALP) and bilirubin (TBL and $\mathrm{DBL}$ ) in the induction control rats (Group $B$ ) when compared to normal control untreated rats (Group A). 
Treatment with 100, 200 and $300 \mathrm{mg} / \mathrm{kg}$ (orally) of $A$. paniculata aqueous leaf extract was marked by significant $(P<0.05)$ decrease in serum levels of marker enzymes (ALT, AST and ALP) and bilirubin (TBL and $\mathrm{DBL}$ ), in a dose - dependent manner, when compared to Group B values. Induction with $\mathrm{CCl}_{4}$ was marked by a significant $(P<0.05)$ decrease in serum levels of total protein (TP) and albumin (ALB). Treatment with 100, 200 and $300 \mathrm{mg} / \mathrm{kg}$ (orally) of $A$. paniculata aqueous leaf extract was marked by significant $(P<0.05)$ increase in serum levels of TP and ALB, in dose dependent manner, when compared to Group B. As shown by the results, $\mathrm{CCl}_{4}$ doses induced acute hepatic damage as evidenced by a marked elevation in the serum levels of the liver enzymes, ALT, AST and ALP, and a significant decrease in the circulatory levels of TP and ALB, which are in conformity with earlier reports of the deleterious biochemical effects of $\mathrm{CCl}_{4}$ on hepatic injury (Fadhel and Amran, 2002; Rajesh and Latha, 2004; Nagano et al., 2007). It is well documented in literature that $\mathrm{CCl}_{4}$ is metabolised by mixed - function oxidase system in the endoplasmic reticulum of the liver to the highly reactive trichloromethyl radical, and this reactive metabolite leads to auto - oxidation of the fatty acids present in the cytoplasmic membrane phospholipids and causes both functional and morphological distortion of the cell membrane (Recknagel and Glende, 1973). The hepatocyte membrane distortion is associated with membrane leakage of the hepatocyte cytosolic contents which is manifested by significant elevation of the serum marker enzymes of acute hepatocellular damage namely ALT and AST, and ALP as a marker for hepatobiliary damage (Bhattacharyya et al., 2003). However, of these marker enzymes, ALT is the most reliable. AST is known to be present in abundance in the cardiac muscle, skeletal muscle, kidneys and testes, and ALP is abundant in the growing bone. Thus, any disease state affecting any of these extrahepatic tissues significantly elevates the serum levels of these enzymes (Friedman et al., 1996). Extract treatment significantly attenuated the acute elevation of these Table 2 shows the dose - dependent preventive effect of oral doses of $A$. paniculata aqueous leaf extract against the deleterious effect of $\mathrm{CCl}_{4}$ intoxication on the serum lipid profile. The liver is known to be involved in the syntheses of triglyceride and cholesterol which are synthesised from a substrate, acetyl CoA (produced through fatty acid oxidation) (West et al., 1966). The hepatoprotective effects of the oral doses of $A$. paniculata aqueous leaf extract were determined using serum triglyceride, total cholesterol, HDL, LDL and VLDL as measuring parameters of liver function since they are synthesised de novo in the liver. Significant $(P<0.05)$ increase in $\mathrm{CHL}, \mathrm{TG}, \mathrm{LDL}$ and VLDL was observed in the $\mathrm{CCl}_{4}$-intoxicated group. Significant $(\mathrm{P}<0.05)$ decrease in $\mathrm{HDL}$ was observed in $\mathrm{CCl}_{4}{ }^{-}$ intoxicated group. The inhibition of protein synthesis and disturbance of phospholipids metabolism might be responsible for the abnormal levels of lipoproteins in the serum. Treatment with aqueous leaf extract of $A$. paniculata significantly reversed these changes. This is an indication that the extract preserved hepatic protein synthesis and phospholipids metabolism.

Enzymes in dose - dependent manner; demonstrating A. paniculata aqueous leaf extract has hepatoprotective effect. $\mathrm{CCl}_{4}$ induction was also associated with significant decrease in the serum levels of albumin and total protein. However, treatment with $A$. paniculata aqueous leaf extract protected the liver from the deleterious effect of the toxin by ameliorating the decrease in the circulatory levels of albumin and total protein in dose - dependent manner. $\mathrm{CCl}_{4}$ induction causes degeneration of hepatocytes and blockade of the bile ducts which result into significant increase in the serum levels of total bilirubin and direct bilirubin (Saraswat et al., 1993). Treatment with A. paniculata aqueous leaf extract normalised the elevated serum levels of total bilirubin and direct bilirubin. Thus, reduction in the levels of ALT and AST towards the normal value is an indication of regeneration process. Reduction in the levels of ALP, total bilirubin and direct bilirubin suggests the stabilisation of the biliary function. An increase in the serum levels of total protein and albumin suggests the stabilisation of endoplasmic reticulum, leading to protein synthesis. Reduced glutathione (GSH) is a naturally occurring substance that is abundant in many living creatures. GSH is an intracellular reductant and plays major role in catalysis, metabolism and transport (Ghosh et al., 2007). GSH functions as free radical scavenger and in the repair of radical caused biological damage (Moron et al., 1979). GSH, through its significant reducing power, contributes to the recycling of other antioxidants such as vitamins $C$ and $E$ that have become oxidised. Reduced GSH is a critical determinant of tissue susceptibility to oxidative damage and the depletion of hepatic GSH has been shown to be associated with an enhanced toxicity to chemicals, including $\mathrm{CCl}_{4}$ (Kidd, 1997). 


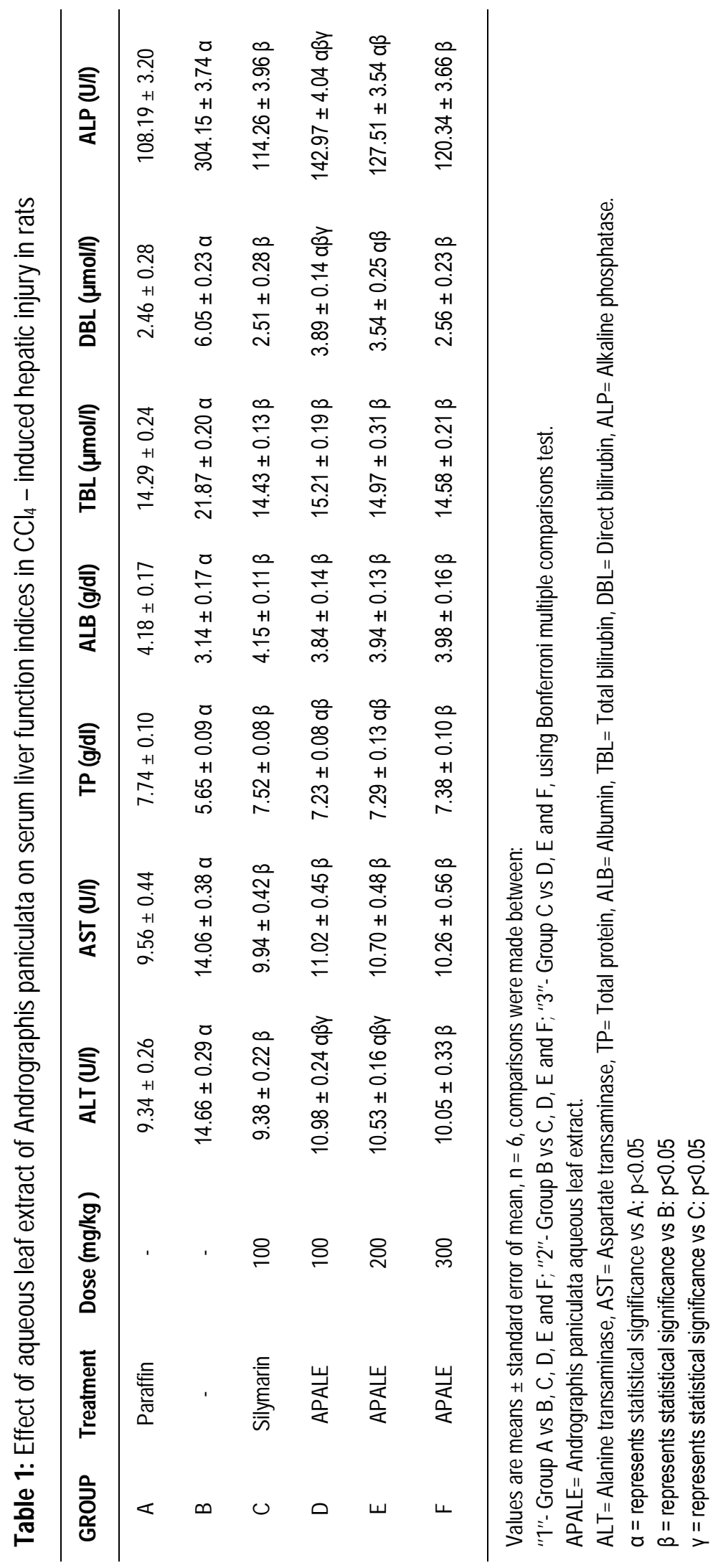




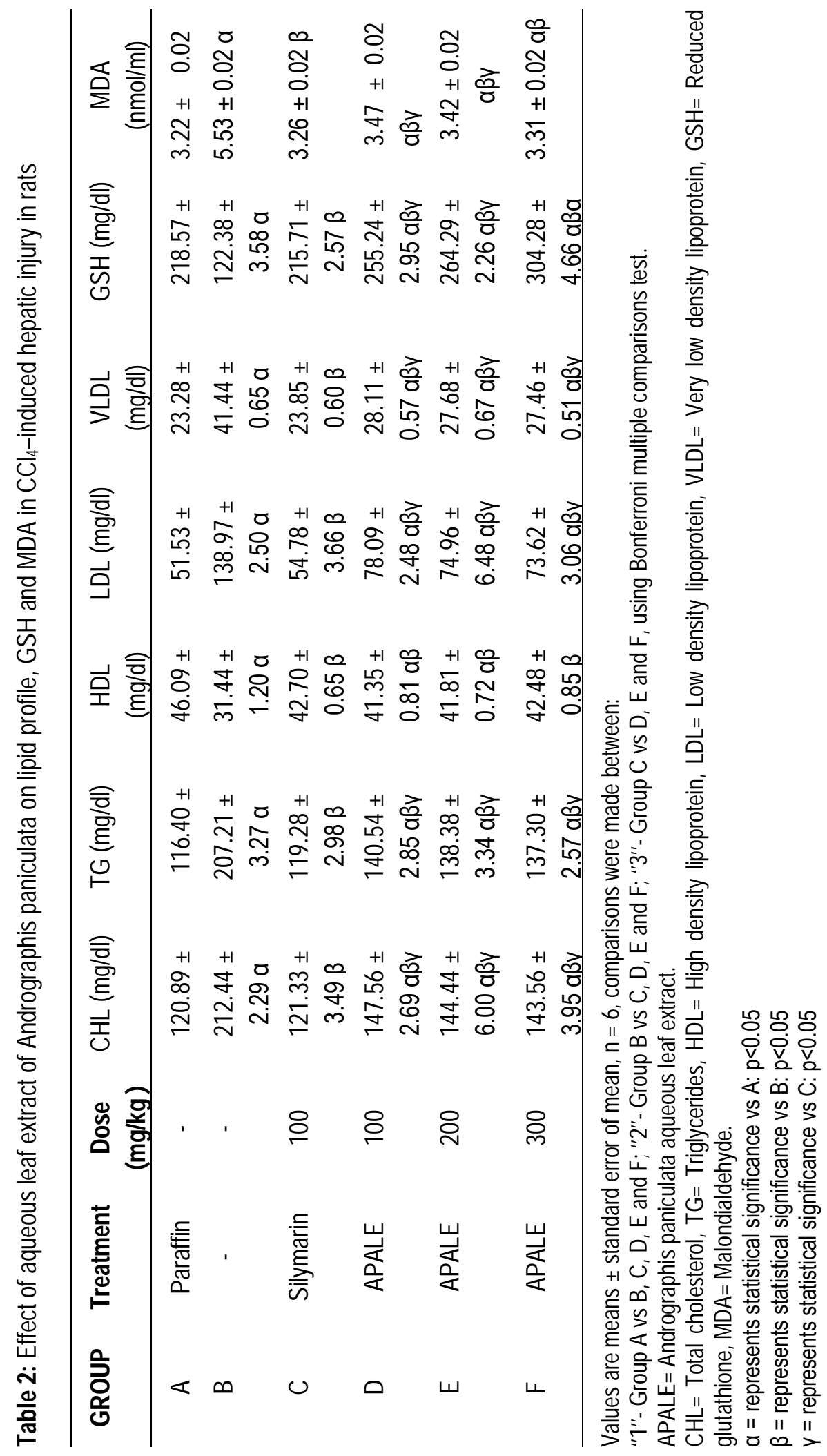


A significant $(p<0.05)$ decrease in hepatic tissue GSH level was observed in the $\mathrm{CCl}_{4}$ treated group while there was significant $(p<0.05)$ increase in GSH level in the groups treated with the plant extract. Hence, exogenous aqueous leaf extract of $A$. paniculata supplementation might provide the means of recovering reduced GSH levels to prevent hepatic injuries. The increase in hepatic GSH level in rats treated with the extract and $\mathrm{CCl}_{4}$ might be due to de novo synthesis or $\mathrm{GSH}$ regeneration.

The level of lipid peroxides is a measure of membrane damage and alterations in structure and function of cellular membranes. A significant $(p<0.05)$ elevation of lipid peroxides in the liver of rats treated with $\mathrm{CCl}_{4}$ was observed. The increase in MDA levels in the liver suggests enhanced lipid peroxidation leading to tissue damage and failure of antioxidant defence mechanisms to prevent the formation of excessive free radicals (Achiliya et al., 2004). Treatment with aqueous leaf extract of $A$. paniculata significantly reversed these changes.

It has been earlier reported that decreasing the metabolic activation of carbon tetrachloride, the antioxidant activity, prevention of generation of reactive oxygen species and scavenging of generated free radicals or by combination of these are important mechanisms in the protection against $\mathrm{CCl}_{4}$-induced hepatic lesion (Yutin et al., 1990; Bhattacharyya et al., 2003). The biochemical and antioxidant findings obtained suggest that the extract might be mediating its protective effects either by decreasing the metabolic activation of carbon tetrachloride, or by acting as a chain - breaking antioxidant for scavenging free radicals or by combination of these effects. Moreover, previous studies have reported that protective effects of hepatoprotective medicinal plants are mediated by their flavonoids or alkaloids components or by their combination via antioxidant and free radicals scavenging activities (Lanhers et al., 1991; Adeneye et al., 2009). The presence of secondary metabolites might thus be accounting for the hepatoprotective effect of $A$. paniculata aqueous leaf extract and could be via antioxidant or free radicals scavenging activities.

The study demonstrated that $A$. paniculata possesses significant hepatoprotective effects and may be source of lead compound in the management of liver diseases. Further studies regarding the isolation and characterisation of the active principles responsible for hepatoprotective properties are recommended.

\section{REFERENCES}

Achiliya, G.S., Wadodkar, S.O. and Dorle, A.K. (2004). Evaluation of hepatoprotective effect of Amakadi ghrita against carbon tetrachloride induced hepatic damage in rats. Journal of Ethnopharmacology, 90: 229-232.

Adeneye, A.A., Olagunju, J.A., Elias, S.O., Olatunbosun, D.O., Mustafa, A.O., Adeshile, O.I., Ashaolu, A.O., Laoye, T.A., Bamigboye, A.O. and Adeoye, A.O. (2009). Protective activities of the aqueous root extract of Harungana madagascariensis in acute and repeated acetaminophen hepatotoxic rats. International Journal of Applied Research in Natural Products, 3: 29-42.

Ahmad, M. and Asmawi, M.Z. (1993). Some pharmacological effects of aqueous extract of Andrographis paniculata Nees. The International Conference on the Use of Traditional Medicine and Other Natural Products in HealthCare. (Abstracts), pp. 122.

Ahsan, R., Islam, M., Bulbul, J. I., Musaddik, A. and Haque, E. (2009). Hepatoprotective activity of Methanol extract of some medicinal plants against carbon tetrachloride-induced hepatotoxicity in rats. European Journal of Scientific Research, 37(2): 302-310.

Alpha Omega Labs. (2008). Andrographis In-depth Review. Alpha Omega Laboratories, Guayaquil, Ecuador. Retrieved November 5, 2009 from http://www.altcancer.com/andcan.htm

Bhattacharyya, D., Mukherjee, R., Pandit, S., Das, N. and Sur, N.K. (2003). Prevention of carbon tetrachloride induced hepatotoxicity in rats by Himoliv, a polyherbal formulation. Indian Journal of Pharmacology, 35: 183- 185.

Bishayee, A., Sarkar, A. and Chartterjee, M. (1995). The hepatoprotective activity of carrot (Daucus carota L.) against carbon tetrachloride in rats. Journal of Pharmacy and Pharmacology, 54: 555-563.

Chang, H.M. and But, P.P.H. (1986). Pharmacology and applications of Chinese material medica. Vol. 1. Singapore, World Scientific, pp.1918-928.

Chang, R.S. and Yeung, H.W. (1988). Inhibition of growth of human immunodeficiency virus in vitro 
by crude extracts of Chinese medicinal herbs. Antiviral Research, 9:163-175.

Chatterjee, T.K. (2000). Medicinal plants with hepatoprotective properties. In: Herbal options, 3ed. Calcuta Books and Allied Publishers Limited, pp.135-137.

Chattopadhyay, R.R. (2003). Possible mechanism of hepatoprotective activity of Azadirachta indica leaf extract. Part II. Journal of Ethnopharmacology, 89(2-3): 217- 219.

Coon, J.T. and Ernst, E. (2004). Andrographis paniculata in the treatment of upper respiratory tract infections: systematic review of safety and efficacy. Planta Medica, 70: 293-298.

Doumas, B.T., Watson, W. and Briggs, H.G. (1971). Albumin standards and the measurement of serum albumin with bromocresol green. Clinica Chimica Acta, 31: 87-96.

Fadhel, Z.A. and Amran, S. (2002). Effects of black tea extract on $\mathrm{CCl}_{4}$-induced lipid peroxidation in liver, kidneys and testes of rats. Phytotherapy Research, 16 (Suppl.1): 28-32.

Friedewald, W. T., Levy, R. I. and Fredrickson, D. S. (1972). Estimation of concentration of low density lipoprotein cholesterol in plasma without use of preparative centrifuge.Clinical Chemistry, 187: 589.

Friedman, L.S., Martin, P. and Muooz, S.J. (1996). Liver function tests and the objective evaluation of the patient with liver disease. In: Hepatology: A Textbook of Liver Disease. Vol. 1, 3ed. Philadelphia: WB Saunders Co., pp. 791-833.

Ghosh, T., Maity, T.K., Das M., Bose, A. and Dash, D.K. (2007). In vitro antioxidant and hepatoprotective activity of ethanolic extract of Bacopa monnieri Linn., aerial parts. Iranian Journal of Pharmacology and Therapeutics, 6: 7-85.

Gornall, A.G., Bardawill C.S. and David M.M. (1949). Determination of serum proteins by means of biuret reaction. Journal of Biological Chemistry, 177: 751.

Gupta, S., Choudhury, M.A., Yadava, J.N.S., Srivastava, V. and Tandon J. S. (1990). Antidiarrhoeal activity of diterpenes of Andrographis paniculata (Kal-Megh) against Escherichia coli enterotoxin in vivo models. International Journal of Crude Drug Research, 28: 273-283.

Gupta, S., Yadava, J.N.S. and Tandon, J.S. (1993). Antisecretory (antidiarrhoeal) activity of Indian medicinal plants against Escherichia coli enterotoxin-induced secretion in rabbit and guinea pig ileal loop models. Pharmaceutical Biology, 31: 198-204.

Handa, S.S. and Sharma, A. (1990). Hepatoprotective activity of andrographolide from Andrographis paniculata against carbontetrachloride. Indian Journal of Medical Research, 92: 276-283.

Hartman, P.E. (1983). Putative mutagens and carcinogens in foods, IV. Malondialdehyde (Malondialdehyde). Environmental Mutagenesis, 5 (4): 603-607.

Jarukamjorn, K. and Nemoto, N (2008). Pharmacological aspects of Andrographis paniculata on health and its major diterpenoid constituent andrographolide. Journal of Health Science 54 (4):370-381..

Jendrassik, L. and Grof, P. (1938). Simplified photometric methods for the determination of bilirubin. Biochem Zschr., 297: 81-89.

Joseph, P.K., Rao, K.R. and Sundaresh, C.S. (1989). Toxic effects of garlic extract and garlic oil in rats. Indian Journal of Experimental Biology, 27: 977-979.

Khan, F. (2007). Andrographis - An Immune Boosting Herb. Retrieved January 22, 2010, from http://ezinearticles.com/?Andrographis---AnImmune-- Boosting- Herb\$id=538001

Khan, F.Z., Asdaq, S.M.B. and Kumar, P.S.R. (2009). Effects of few Indian medicinal herbs on carbon tetrachloride induced injury in animals. International Journal of Pharm. Tech Research, 1 (3). 579-587.

Kidd, P.M. (1997). Glutathione systemic protestant against oxidative and free radical damage. Alternative Medicine Review, 2: 155-176.

Kumar, R.A., Sridevi, K., Kumar, N.V., Nanduri, S. and Rajagopal, S. (2004). Anticancer and mmunostimulatory compounds from Andrographis paniculata. Journal of Ethnopharmacology, 92:291-295.

Lanhers, M.C., Joyeux, M., Soulimani, R., Fleurentin, J., Sayag, M., Mortier, F. And Younos, C. (1991). Hepatoprotective and anti-inflammatory effects of a traditional medicinal plant of Chile, Pneumus boldus. Planta Medica, 57: 110-115.

Lopez - Virella, M.F., Stone, P., Ellis, S. and Colwell, J.A. (1977). Cholesterol determination in high density lipoproteins separated by three different methods. Clinical Chemistry, 23: 882-884. 
Mandal, S.C., Dhara, A.K. and Maiti, B.C. (2001). Studies on psychopharmacological activity of Andrographis paniculata extract. Phytotheraphy Research, 15: 253-256.

Mascolo, N., Sharma, R., Jain, S.C. and Capasso, F. (1988). Ethnopharmacology of Calotropis procera flowers. Journal of Ethnopharmacology, 22: 211-221.

Mishra, U.S., Mishra, A., Kumari, R., Murthy, P.N. and Naik, B.S. (2009). Antibacterial activity of ethanol extract of Andrographis paniculata. Indian Journal of Pharmaceutical Sciences, 71: 436-438.

Misra, P., Pal, N.L., Guru, P.Y., Katiyar, J.C., Srivastava, V. and Tandon, J.S. (1992). Antimalarial activity of Andrographis paniculata (Kalmegh) against Plasmodium berghei NK 65 in Mastomys natalensis. International Journal of Pharmacognosy, 30: 263-274.

Moron, M.S., Depierre, J.W. and Manmerik, B. (1979). Level of glutathione, glutathione reductase and glutathione-s-transferase activity in rat lung and liver. Biochimica et Biophysica Acta, 582: 67-78.

Nagano, K., Umeda, Y., Saito, M., Nishizawa, T., Ikawa, N., Arito, H., Yamamoto, S. and Fukushima, S. (2007). Thirteen-week inhalation toxicity of carbon tetrachloride in rats and mice. Journal of Occupational Health, 49: 249259.

Nan, J.X., Park E.J., Kim, V.C., and Sohn, D.H. (2002). Scutellaria baicalensis inhibits liver fibrosis induced by bile duct ligation or carbon tetrachloride in rats. Journal of Pharmacy and Pharmacology, 54:555-563.

Norhaida, A.H. (1994). The effect of different fractions of Andrographis paniculata extract on blood glucose level in diabetic rats. (Bachelor of Science Project Report). Department of Biology, UPM Malaysia, Malaysia.

OECD (2001). Acute Oral Toxicity - Up - and - Down Procedure (UDP). OECD Guidelines for the Testing of Chemicals.

Oyagbemi, A.A. and Odetola, A.A. (2010). Hepatoprotective effects of ethanolic extract of Cnidoscolus aconitifolius on paracetamol induced hepatic damage in rats. Pakistan Journal of Biological Sciences, 13(4). 164-169.

Patarapanich, C., Laungcholatan, S., Mahaverawat, N., Chaichantipayuth, C. and Pummangura, S. (2007). HPLC determination of active diterpene lactones from Andrographis paniculata Nees planted in various seasons and regions in Thailand. Thai Journal of Pharmaceutical Sciences, 31:91-99.

Patterson, J.W. and Lazarow, A. (1955). Methods of Biochemical Analysis. Glick D. (ed). New York, Inter Science, 2: 259.

Prakash, T., Faladu, S.D., Sharma, U.R., Surendra, V., Goli, D., Stamina, P. and Kotresha, D. (2008). Hepatoprotective activity of leaves of Rhododendron arboretum in $\mathrm{CCl}_{4}$ induced hepatotoxicity in rats. Journal of medicinal Plants Research 2 (11). 315-320.

Puri, A., Saxena, R., Saxena, R.P. and Saxena, K.C. (1993). Immunostimulant agents from Andrographis paniculata. Journal of Natural Products, 56: 995-999.

Rajesh, M.G. and Latha, M.S. (2004). Protective activity of Glycyrrhiza glabra Linn. on carbon tetrachloride - induced peroxidative damage. Indian Journal of Pharmacology, 36: 284-287.

Rao, G.M.M., Rao, C.V., Pushpangadan, P. and Shirwaikar, A. (2005). Hepatoprotective effects of rubiadin, a major constituent of Rubia cordifolia Linn. Journal of Ethnopharmacology, 103 (3). 483-490.

Recknagel, R.O. and Glende, E.A. Jr. (1973). Carbon tetrachloride hepatotoxicity: An example of lethal cleavage. CRC. Critical Reviews in Toxicology, 2: 263-297.

Reitman, S. and Frankel, A.S. (1957). A colorimetric method for determination of serum glutamic oxaloacetic and glutamic pyruvic transaminase. American Journal of Clinical Pathology, 28: 5663.

Sabu, K.K. (2006). Intraspecific variation of Andrographis paniculata Nees. (Doctoral thesis, University of Kerala, 2006). Retrieved from http://sabuthesis.thesiencenet.com

Sakila, S., Begum, N., Kawsar, S., Begum, Z.A., and Zoha, M.S. (2009). Relationship of antifertility effects of Andrographis paniculata and hormonal assay in female rats. Bangladesh Journal of Medical Science 8 (1-2). 10-14.

Sandberg, F. (1994). Andrographidis herba Chuanxinlian. A Review. Swedish Herbal Institute, Gothenburg, Sweden.

Saraswat, B., Visen, P.K., Patnaik, G.K., Dhawan, B.N. (1993). Anticholestic effect of picroliv, active hepatoprotective principle of Picrorhiza kurroa, against carbon tetrachloride induced cholestatis. 
Indian Journal of Experimental Biology, 31: 316371.

Selvanayagam, Z.E., Gnavavendhan, S.G., Chandrasekkharan, P., Balakrishna, K. and Rao, B.R. (1994). A review on pharmacological and clinical studies. Fitoterapia 65 (2). 99-111.

Sood, R. (1999). Medical Laboratory Technology, Methods and Interpretation. 5ed. Jaypee Brothers Medical Publishers Ltd., pp. 488-490.

Stephen, H. and Comac, L. (2000). Miracle herbs: How herbs combine with modern medicine to treat cancer, heart disease, AIDS, and more, Kensington Publishing Corporation, New York.

Tan, B.K.H. and Zhang, C.Y. (2004). Andrographis paniculata and the cardiovascular system. In Herbal and Traditional Medicine: Molecular Aspects on Health. CRC Press, Teipei, pp. 441456.

Tietz, N.W. (1990). Clinical Guide to Laboratory Tests, 2ed. W. B. Saunders Company, Philadelphia, USA, pp. 554-556.

Timbrell, J.A. (1987). Principles of Biochemical Toxicology. Taylor and Francis Ltd, London, pp. 140-143, 184-189.

Trinder, P. (1969). A colorimetric method of determination of serum and plasma cholesterol. Annals of Clinical Biochemistry, 6: 24-27.

Trivedi, N. and Rawal, U.M. (2000). Hepatoprotective and toxicological evaluation of Andrographis paniculata on severe liver damage. Indian Journal of Pharmacology, 32: $\quad$ 288-293.

Vedavathy, S. and Rao, K.N. (1991). Antipyretic activity of six indigenous medicinal plants of Tirumala
Hills, Andhra Pradesh, India. Journal of Ethnopharmacology, 33: 193-196.

Ward, F.M. and Daly, M.J. (1999). Hepatic Disease. In: Clinical Pharmacy and Therapeutics (Walker R. And C. Edwards Eds.). Churchill Livingstone, New York, pp. 3346-3347.

West, E.E., Todd, W.R., Mason, H.S. and Van Bruggeu, J.T. (1966). Textbook of Biochemistry, 4ed. London: The Macmillan Company, pp. 10171118.

Wiart, C., Kumar, K., Yusof, M.Y., Hamimah, H., Fauzi, Z.M. and Suleman, M. (2005). Antiviral properties of ent-labdene diterpenes of Andrographis paniculata Nees, inhibitors of herpes simplex virus type 1. Phytotherapy Research, 19: 1069-1070.

Wolf, P.L. (1999). Biochemical diagnosis of liver diseases. Indian Journal of Clinical Biochemistry 14, pp. 59-90.

Yadav, N.P. and Dixit, V.K. (2003). Hepatoprotective activity of leaves of Khalanchoe pinnata pers. Journal of Ethnopharmacology, 86: 197-202.

Yeung, S.C.S., Yao, S.C. and Wang, L.L. (1987). Pharmacology and Applications of Chinese Materia Medica, Vol. 2, World Scientific Publishing Co. Pte. Ltd., Singapore.

Yutin, C., Rongliang, Z., Zhongjian, J. and Yong, J. (1990). Flavonoids as superoxide scavengers and antioxidants. Free Radicals Biology and Medicine, 9: 19-23.

Zhang, X.F. and Tan, B.K. (2000). Anti-diabetic property of ethanolic extract of Andrographis paniculata in streptozotocin-diabetic rats. Acta. Pharmacologica Sinica, 21:1157-1164. 